\title{
PNPLA3 Polymorphism Directly Affects the Susceptibility of Genotype 4-Induced HCV Infection and Its Progression to Liver Fibrosis Among the Egyptian Patients
}

\author{
Samar Samir Youssef ${ }^{1 *}$, Eman Abd El Razek Abbas ${ }^{1}$, Moustafa Nouh Elemeery ${ }^{1-3}$, Rana Ahmed Youness ${ }^{4}$, Amal \\ Soliman Nasr ${ }^{5}$ and Sameh Seif ${ }^{6}$ \\ ${ }^{1}$ Microbial Biotechnology Department, National Research Centre, Egypt \\ ${ }^{2}$ Centre for Systemic Biotechnology, Korea Institute of Science and Technology, Republic of Korea \\ ${ }^{3}$ Division of Biomedical Science and Technology, Korea University of Science and Technology, Republic of Korea \\ ${ }^{4}$ Pharmaceutical Biology Department, Faculty of Pharmacy and Biotechnology, German University in Cairo, Cairo, Egypt \\ ${ }^{5}$ Clinical and Chemical Pathology Department, Faculty of Medicine, Cairo University, Egypt \\ ${ }^{6}$ National Hepatology and Tropical Medicine Research Institute, Cairo, Egypt \\ *Corresponding author: Samar Samir Youssef, Microbial Biotechnology Department, National Research Centre, Egypt
}

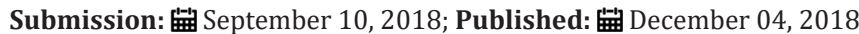

\begin{abstract}
Introduction: Chronic Hepatitis C (CHC) infection is associated with liver fibrosis, cirrhosis, hepatocellular carcinoma, and eventually death. Genetic risk factors have been casted as predictors of the severity and progression of several CHC-associated liver diseases. PNPLA3 (rs738409), a novel genetic marker strongly associated with increased fat content in the liver. Nonetheless, recognition of an association between PNPLA3 rs73409 (C>G) and the severity of fibrosis in $\mathrm{CHC}$ has been inadequately studied.
\end{abstract}

Aim: To investigate the impact of PNPLA3 rs73409 (C>G) polymorphism on susceptibility to HCV infection and on liver fibrosis progression.

Methods: 351 individuals were genotyped for rs73409 (C>G) by TaqMan allelic discrimination assay, among them 175 were HCV patients and 176 healthy controls.

Result: A statistically significant correlation $(\mathrm{p}=0.001)$ was found between the genotype distribution of rs73409 $(\mathrm{C}>\mathrm{G})$ in healthy individuals versus HCV patients. Moreover, among HCV individuals, the distribution of GG genotype showed statistically significant difference ( $\mathrm{P}=0.042)$ in low grade versus high grade and is more frequent in advanced fibrosis. Gender related differential effect of rs73409 $(C>G)$ genotype was reported in susceptibility to HCV and degree of liver fibrosis.

Conclusion: PNPLA3 rs73409 (C>G) polymorphism affects susceptibility to infection by HCV and fibrosis progression in Egyptian genotype 4 HCV patients.

Keywords: PNPLA3; HCV; Polymorphism; Susceptibility to HCV; Liver fibrosis

Key Points

The PNPLA3 rs73409 homozygous CC genotype is 2.19 times more among patients than controls, indicating a role of this genotype in susceptibility to HCV especially in females. The PNPLA3 rs73409 homozygous genotype GG was associated within advanced fibrosis in HCV patients. When stratified according to gender, the GG genotypes is associated with advanced fibrosis in males only but not females. The PNPLA3 rs73409 can be used as risk factor to identify individuals at high risk of HCV infection and HCV patients at risk of severe fibrosis.

\section{Introduction}

Hepatitis $\mathrm{C}$ virus ( $\mathrm{HCV}$ ) is a worldwide prevailing pathogen and a primary cause of mortality in many cases [1]. According to a recent epidemiological study, it was reported that the virus seroprevalence has been increased over that last 15 years, equating to more than 185 million cases of infections worldwide [2]. Persistent HCV infection is associated with the development of several liver related morbidities such as liver fibrosis, liver cirrhosis, hepatocellular carcinoma, liver failure, and eventually death [3]. Yet, the clinical outcome of chronic hepatitis C (CHC)-related liver diseases is highly variable [4]. The severity of liver diseases in CHC patients can be correlated with several risk factors such as male gender, old age, insulin resistance, high body mass index (BMI), chronic alcohol consumption, and most importantly viral factors (especially HCV genotype 4 in Middle East) [5-8]. However, even when all these 
factors are combined; an overall prediction rate of less than $30 \%$ was achieved [9]. Thus, intensive research has now turned to unveil the association of genetics and ethnicity with disease prediction and progression.

Genetic risk factors have been casted as potential determinants and predictors of the severity and progression of several CHCassociated liver diseases. In 2008, Romeo and his colleagues ran an independent genome-wide survey of non-synonymous sequence variations to identify genetic determinants of specific liver associated disease known as liver steatosis [10]. Liver steatosis is a frequent condition among patients with CHC virus infection, its prevalence is significantly escalating nowadays among the CHC patients [11]. It has been associated with patients with poor sustained viral response and more advanced liver fibrosis [11]. The best documented single nucleotide polymorphism (SNP) in the Romeo et al. [10] study was the polymorphism rs738409 $(\mathrm{C}>\mathrm{G})$ of patatin-like phospholipase domain-containing protein 3 (PNPLA3), encoding the 148 isoleucine to methionine protein variant (p.I148M) [12]. PNPLA3 (rs738409) was identified as a novel genetic marker strongly associated with increased fat content in the liver [12]. Since then PNPLA3 (rs738409) variant has been the focus of several studies unveiling its association with other liver diseases severity.

Nonetheless, recognition of an association between PNPLA3 rs738409 (C>G) and the persistence and severity of liver steatosis or fibrosis in $\mathrm{CHC}$ has been highly controversial. Reports have indicated that carrying the GG genotype of PNPLA3 rs738409 (C>G) among the $\mathrm{CHC}$ patients increase their risk to develop liver fibrosis
[12-14]. However, different opposing set of results were shown in other studies [15]. Not to mention the fact that even among the reports that showed a significant correlation, the strength of the correlation varied, ranging from 1.88 [14] to 7.53 [16] odds ratios (ORs) for advanced liver fibrosis.

It has been recently documented that the PNPLA3 rs738409 (C>G) polymorphism distribution exhibits statistically significant differences according to ethnicity [17] and up to our knowledge the genotype frequency of this polymorphism is inadequately studied in normal and HCV Egyptians. Thus, our aim in this study was to unravel such controversy concerning PNPLA3 rs738409 and its association with liver fibrosis among the Egyptian HCV (Genotype 4) infected patients. Moreover, this study also focused on investigating the correlation of PNPLA3 rs738409 and HCV susceptibility in the same group of patients.

\section{Materials and Methods}

\section{Patients}

A total number of (351) individuals were enrolled in the study, including (175) consecutive G4 HCV-infected patients with detectable anti-HCV antibodies and detectable HCV RNA (Figure 1). Patients were collected from the National Hepatology and Tropical Medicine Research Institute, Cairo, Egypt. The remaining (176) individuals were healthy donors collected from the faculty of Medicine, Cairo University; these were negative for both hepatitis $\mathrm{C}$ and $\mathrm{B}$ viruses and HIV, with no evidence of any other diseases. HCVinfected patients met the following inclusion criteria:

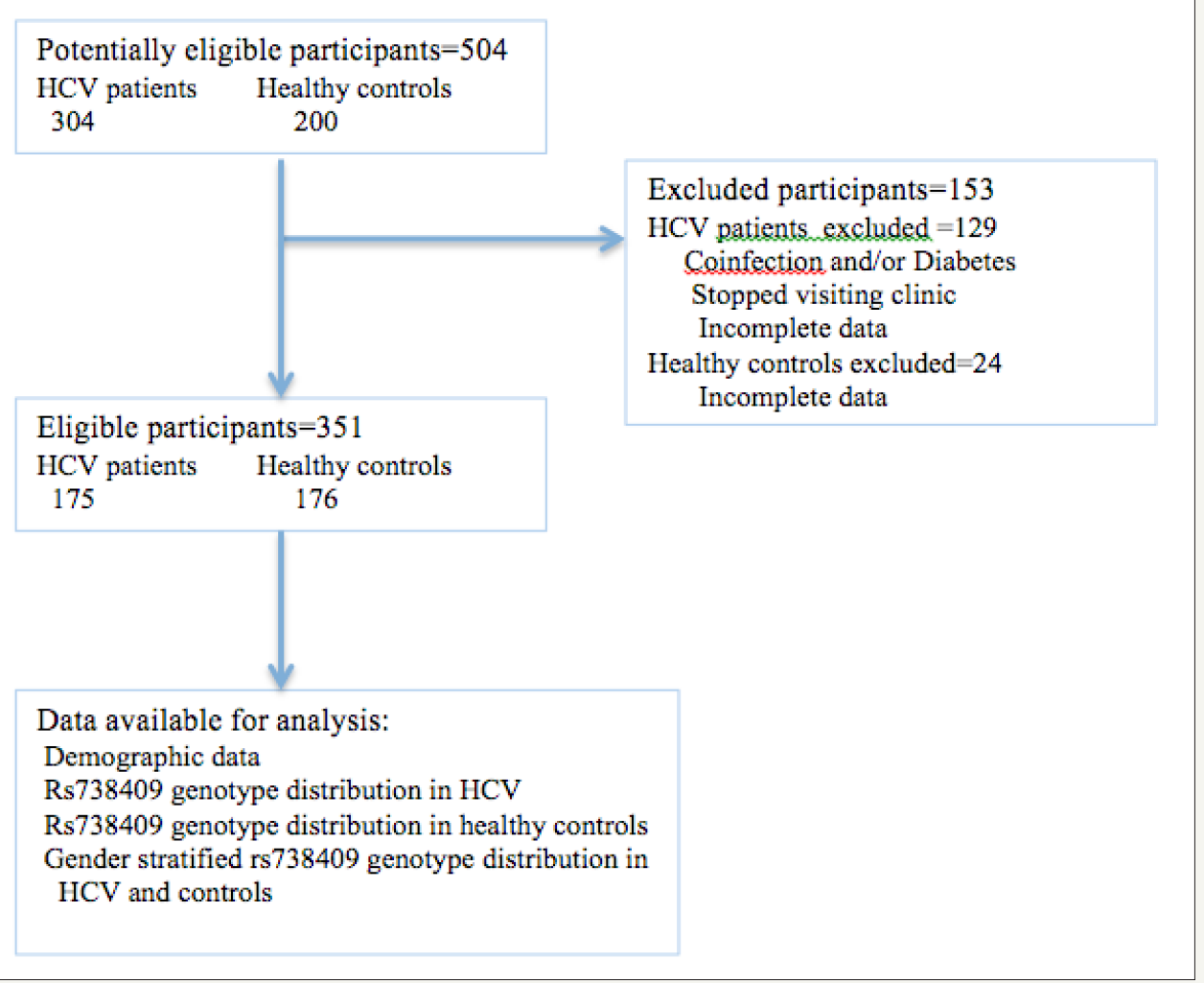

Figure 1: Participants flow during the study. 
1. G4 HCV-infected,

2. Lack of co-infection with other viral infections (HBV, HIV, $\mathrm{EBV}$, and CMV),

\section{Not suffering from bilharzias, and}

4. No history any haematological or autoimmune disorders.

The selection criteria for healthy controls were

a. Lack of HCV Ab in serum,

b. No bilharzias, and

c. Absence of any autoimmune diseases or any haematological disorders.

Fibrosis was assessed by FIB4 score. Some patients had a biopsy report assessed by metavir. This study was approved by the local research ethics committee and a written informed consent was obtained from all participants in this study.

\section{Samples collection and DNA isolation}

Two ml of peripheral venous blood was withdrawn from each participant included in this study. This was performed using sterile anticoagulant tubes. Genomic DNA was extracted using the salting out technique as previously described previously [18]. Informed consent: Informed consent was obtained from all individual participants included in the study.

\section{Genotyping of PNPLA3 rs738409 polymorphism}

A predesigned TaqMan assay (Applied Biosystems, Foster City, CA, USA) was purchased for genotyping of rs738409 which was performed according to the manufacturer' s protocol. HCV genotypes were determined using specific PCR as described [19].

\section{Statistical analysis}

Results were presented as means \pm SD (standard deviation). Student t-tests were used to compare means for both continuous variables and non-normally distributed continuous variables. Comparison between distributions of categorical variables was performed using Chi-square (w2) method. Moreover, variables were described as odds ratio (OR) with 95\% confidence interval (95\% $\mathrm{CI})$ where appropriate. A $\mathrm{P}$ value less than 0.05 was considered statistically significant. ${ }^{* * *}=\mathrm{P}<0.001,{ }^{* *}=\mathrm{P}<0.01,{ }^{*}=\mathrm{P}<0.05$ and ns=statistically not significant. All the data were statistically analyzed using SPSS computer program (version 16 windows) (SPSS Inc., Chicago, IL, USA).

\section{Result}

\section{Demographic data}

Demographic data from HCV patients and healthy control individuals are summarized in Table 1 , age was slightly higher in HCV patients than control $(46.61 \pm 10.46$ versus $40.5 \pm 12.96$ respectively) and male gender was slightly more represented in HCV patients (50.57\% versus $42.2 \%$ respectively), but these differences were not statistically different. All fibrosis stages were adequately represented (Table 1 )
Table 1: Demographic data.

\begin{tabular}{|c|c|c|}
\hline Parameter & HCV Patients & Control \\
\hline Age $($ mean $\pm S D)$ & $46.61 \pm 10.46$ & $40.5 \pm 12.96$ \\
\hline Gender: male $\%$ & $50.57 \%$ & 42.2 \\
\hline $\mathrm{BMI}\left(\mathrm{Kg} / \mathrm{m}^{2}\right.$ mean $\left.\pm \mathrm{SD}\right)$ & $28.66 \pm 4.25$ & $28.2 \pm 3.6$ \\
\hline $\begin{array}{l}\text { Haemoglobin (U/ } \\
\text { Lmean } \pm \text { SD) }\end{array}$ & $13.6 \pm 1.6$ & $12.265 \pm 1.11$ \\
\hline $\begin{array}{l}\text { Total Bilirubin (U/ } \\
\text { Lmean } \pm \text { SD) }\end{array}$ & $0.8(0.12-6.53)$ & \\
\hline PLT $\left(1000 \mathrm{~mm}^{3} /\right.$ mean \pm SD $)$ & $176 \pm 500$ & $280 \pm 1840$ \\
\hline $\begin{array}{l}\text { Baseline ALT (IU/L) } \\
(\text { mean } \pm \text { SD })\end{array}$ & $64(15-370) \pm 38.9$ & $23.34 \pm 9.8$ \\
\hline $\begin{array}{l}\text { Baseline AST (IU/L) } \\
\quad(\text { mean } \pm \text { SD })\end{array}$ & $61.5(10-241) \pm 32.5$ & $23.27 \pm 9.17$ \\
\hline $\mathrm{TLC}^{*}(10 / \mu \mathrm{l})^{3}$ mean $\left.\pm \mathrm{SD}\right)$ & $5700(2.3-10200) \pm 1.9$ & $8.22 \pm 2.3$ \\
\hline $\mathrm{AFP}^{*} \mathrm{ng} / \mathrm{ml}(\mathrm{mean} \pm \mathrm{SD})$ & $5.6(0.01-195.75) \pm 30$ & \\
\hline Creatinine $($ mean \pm SD) & $0.85 \pm 0.19$ & \\
\hline Albumin (mean \pm SD) & $3.97 \pm 0.86$ & \\
\hline Prothrombin (mean \pm SD) & $86.57 \pm 13.44$ & \\
\hline $\begin{array}{l}\mathrm{HCV} \text { viral load IU/ml } \\
\text { (median) }\end{array}$ & $202000(8-23300000)$ & \\
\hline \multicolumn{3}{|c|}{ Fibrosis $\%$} \\
\hline $\mathrm{F} 1$ & $30.5 \%$ & \\
\hline $\mathrm{F} 2$ & $19.5 \%$ & \\
\hline F3 & $29.9 \%$ & \\
\hline $\mathrm{F} 4$ & $20.1 \%$ & \\
\hline
\end{tabular}

*SD: Standard Deviation; BMI: Body Mass Index; TLC: Total Leukocytic Count; ALT: Alanine Amino Transferase; AST: Aspartate Amino Transferase; PLT: Platelet Count; AFP: Alfa Feto Protein

\section{Frequency of PNPLA3 genotypes in Egyptians}

Among the studied 175 healthy control individuals, unexpectedly, the wild type homozygous genotype was detected in $32.4 \%$ of them, while the heterozygous CG genotype was seen in $59.1 \%$ of them and only $8.5 \%$ were homozygous for the mutant genotype GG. The minor allele frequency (MAF) represented by $\mathrm{G}$ allele was calculated to be (0.38) in controls and (0.29) in HCV patients (Table 2).

Table 2: PNPLA3 genotype distribution in HCV patients versus control.

\begin{tabular}{|c|c|c|c|}
\hline $\begin{array}{l}\text { PNPLA3 } \\
\text { Genotype }\end{array}$ & HCV n (\%) 175 & Control n (\%)176 & $\mathbf{P}$ \\
\hline $\mathrm{CC}$ & $91(52 \%)$ & $57(32.4 \%)$ & \multirow{3}{*}{0.001} \\
\hline CG & $66(37.7 \%)$ & $104(59.1 \%)$ & \\
\hline GG & $18(10.3 \%)$ & $15(8.5 \%)$ & \\
\hline $\begin{array}{c}\mathrm{CC} \\
\mathrm{CG}+\mathrm{GG}\end{array}$ & $\begin{array}{l}91(52 \%) \\
84(48 \%)\end{array}$ & $\begin{array}{l}57(32.4 \%) \\
120(67.6 \%)\end{array}$ & 0.001 \\
\hline
\end{tabular}




\begin{tabular}{|c|c|c|c|}
\hline C (Freq) & 0.71 & 0.62 & 0.041 \\
G (Freq) & 0.29 & 0.38 & \\
\hline
\end{tabular}

n: Number; p: P value; \%: Percent

\section{Effect of PNPLA3 genotype distribution on susceptibility to $\mathrm{HCV}$}

Results of PNPLA3 rs738409 genotype frequencies in HCV patients compared to healthy controls are shown in Table 2. In both healthy control and HCV patients, PNPLA3 rs738409 genotype distribution was in hardy-Weinberg equilibrium. A differential distribution of PNPLA3 rs738409 genotypes was recorded between HCV patients and healthy control individuals, this difference was statistically significant $(p=0.001)$ as shown in Table 2 . The homozygous CC genotype was significantly more prevalent in HCV patients $(52 \%)$ than healthy individuals $(32.4 \%$, Table 2$)$. The odds of being homozygous CC is 2.19 times more among patients than controls, indicating a role of this genotype in susceptibility to HCV. When PNPLA3 rs738409 genotype frequencies were stratified according to gender, the difference in genotype distribution was significantly statistically different between patients and healthy individuals in females $(\mathrm{p}=0.001)$ only but not in males $(\mathrm{p}=0.081$; (Table 3)). Moreover, the $G$ allele showed statistically significant $(p=0.001)$ frequency between control and HCV, being more prevalent in controls, which proposes it has a protective effect from susceptibility to HCV and is also confirmed by higher frequency of the homozygous CC genotype in patient females (54.7\%) than control females (27\%).

Table 3: Differential distribution of PNPLA3 genotype according to gender in control compared to HCV patients.

\begin{tabular}{|c|c|c|c|c|}
\hline Gender & Genotype & Control n (\%) & Infected n (\%) & $\mathbf{p}$ \\
\hline \multirow{5}{*}{ Male } & $\mathrm{CC}$ & $29(39.7 \%)$ & $44(50 \%)$ & \multirow{3}{*}{0.081} \\
\hline & CG & $38(52.1 \%)$ & $31(35.2 \%)$ & \\
\hline & GG & $6(8.2 \%)$ & $13(14.8 \%)$ & \\
\hline & $\mathrm{C}$ allele & 0.66 & 0.68 & 0.117 \\
\hline & G allele & 0.34 & 0.32 & 0.499 \\
\hline \multirow{5}{*}{ Female } & $\mathrm{CC}$ & $27(27 \%)$ & $47(54.7 \%)$ & \multirow{3}{*}{0.001} \\
\hline & CG & $64(64 \%)$ & $34(39.5 \%)$ & \\
\hline & GG & $9(9 \%)$ & $5(5.8 \%)$ & \\
\hline & $\mathrm{C}$ allele (freq) & 0.59 & 0.74 & 0.524 \\
\hline & G allele(freq) & 0.41 & 0.26 & 0.001 \\
\hline
\end{tabular}

n: Number; p: P value; \%: Percent, freq: Frequency

Correlation between PNPLA3 genotype distribution and liver fibrosis in HCV patients and gender impact

Results in this study showed difference in genotype distribution of PNPLA3rs 738409 among high and low grades of fibrosis in HCV patients. This difference was statistically significant $(p=0.036$, (Table 4)) and the homozygous genotype GG was more frequent in advanced fibrosis (F4) as present in $17.1 \%$ of them while was in $7.9 \%$ of F1-F3 group; on the contrary the CC genotype was found in $56.8 \%$ of (F1-F3) group compared to $34.3 \%$ in F4 group.
Upon stratification PNPLA3 rs738409 genotypes distribution in HCV according to gender and fibrosis, the difference in genotype frequencies was statistically significant in males only $(p=0.002)$ but not in females ( $p=0.39$, (Table 5)). Moreover, the GG genotype showed higher frequency (40\%) in males with advanced fibrosis (F4) compared to $17.2 \%$ in males with early (F1). On the other hand, in females the GG genotype was in $12.5 \%$ of $\mathrm{F} 1$ patients compared to $0 \% \mathrm{~F} 4$ patients but this difference in genotype frequency was not significant. Indicating a differential distribution according to gender.

Table 4: Distribution of PNPLA3 genotypes in HCV patients according to fibrosis degree.

\begin{tabular}{|c|c|c|c|c|c|}
\hline \multirow{2}{*}{ Genotype } & \multicolumn{4}{|c|}{ Fibrosis } & \multirow{2}{*}{$\mathrm{p}$} \\
\hline & F1n (\%) & F2n (\%) & F3n (\%) & F4n (\%) & \\
\hline CC & 31 (58.5\%) & $18(52.9 \%)$ & $30(57.7 \%)$ & $12(34.3 \%)$ & \multirow{2}{*}{0.042} \\
\hline CG & $14(26.4 \%)$ & $15(44.1 \%)$ & $20(38.5 \%)$ & $17(48.6 \%)$ & \\
\hline \multirow[t]{2}{*}{ GG } & $8(16.3 \%)$ & $1(2.9 \%)$ & $2(3.8 \%)$ & $6(17.1 \%)$ & \multirow{5}{*}{0.036} \\
\hline & \multicolumn{3}{|c|}{ F1-F3 } & F4 & \\
\hline $\mathrm{CC}$ & \multicolumn{3}{|c|}{79 (56.8\%) } & $12(34.3 \%)$ & \\
\hline CG & \multicolumn{3}{|c|}{49 (35.5\%) } & $17(48.6 \%)$ & \\
\hline GG & \multicolumn{3}{|c|}{$11(7.9 \%)$} & $6(17.1 \%)$ & \\
\hline
\end{tabular}

n: Number; p: P value; \%: Percent; F: Liver Fibrosis 
Table 5: PNPLA3 genotypes distribution in fibrotic HCV patients according to gender.

\begin{tabular}{|c|c|c|c|c|c|c|}
\hline \multirow{2}{*}{ Gender } & \multirow{2}{*}{ Genotype } & \multicolumn{4}{|c|}{ Fibrosis } & \multirow[t]{2}{*}{$\mathrm{p}$} \\
\hline & & $\mathrm{F} 1$ & $\mathrm{~F} 2$ & F3 & $\mathrm{F} 4$ & \\
\hline \multirow{3}{*}{ Male } & CC & $16(55.2 \%)$ & $8(47.1 \%)$ & $16(57.1 \%)$ & $4(26.7 \%)$ & \multirow{3}{*}{0.002} \\
\hline & CG & $8(27.6 \%)$ & $9(52.9 \%)$ & $11(39.3 \%)$ & $5(33.3 \%)$ & \\
\hline & GG & $5(17.2 \%)$ & $0(0.0 \%)$ & $1(3.6 \%)$ & $6(40.0 \%)$ & \\
\hline \multirow{3}{*}{ Female } & $\mathrm{CC}$ & $15(62.5 \%)$ & $10(58.8 \%)$ & $14(53.8 \%)$ & $8(40.0 \%)$ & \multirow{3}{*}{0.390} \\
\hline & CG & $6(25 \%)$ & $6(35.3 \%)$ & $11(42.3 \%)$ & $12(60.0 \%)$ & \\
\hline & GG & $3(12.5 \%)$ & $1(5.9 \%)$ & $1(3.8 \%)$ & $0(0.0 \%)$ & \\
\hline
\end{tabular}

n: Number; p: P value; \%: Percent; F: Liver Fibrosis

Correlation between PNPLA3 genotype distribution and biochemical parameters in $\mathrm{HCV}$ patients

In the HCV patients studied herein, the correlation of PNPLA3 rs738409 genotype distribution showed border line $(\mathrm{p}=0.057)$ statistical correlation with ALT, but didn't significantly differ with other studied biochemical parameters as PLT,Hb, INR and viremia (Table 6).

Table 6: Correlation of PNPLA3 genotypes and Biochemical parameters.

\begin{tabular}{|c|c|c|c|c|}
\hline Parameter & Gene 1 & $\mathrm{n}$ & Median (Min.-Max.) & P Value \\
\hline \multirow{3}{*}{ PLT } & $\mathrm{CC}$ & 90 & $182000(50000-396000)$ & \multirow{3}{*}{0.674} \\
\hline & CG & 66 & $182000(44000-417000)$ & \\
\hline & GG & 17 & $145000(67000-318000)$ & \\
\hline \multirow{3}{*}{$\mathrm{Hb}$} & $\mathrm{CC}$ & 91 & $13.2(10-16.8)$ & \multirow{3}{*}{0.485} \\
\hline & CG & 66 & $13.7(9.6-16.4)$ & \\
\hline & GG & 17 & $14.1(11-16.5)$ & \\
\hline \multirow{3}{*}{ ALT } & $\mathrm{CC}$ & 91 & $60(15-370)$ & \multirow{3}{*}{0.057} \\
\hline & CG & 66 & $58(17-133)$ & \\
\hline & GG & 17 & $86(22-233)$ & \\
\hline \multirow{3}{*}{ INR } & $\mathrm{CC}$ & 30 & $1.04(1-1.3)$ & \multirow{3}{*}{0.109} \\
\hline & CG & 22 & $1.12(1-2.15)$ & \\
\hline & GG & 5 & $1.15(1-1.24)$ & \\
\hline \multirow{3}{*}{ Viremia } & $\mathrm{CC}$ & 91 & $281000(100-15000000)$ & \multirow{3}{*}{0.239} \\
\hline & CG & 66 & $319349(59-23300000)$ & \\
\hline & GG & 18 & $79816.5(8-4240000)$ & \\
\hline
\end{tabular}

N: Number; PLT: Platelet; Hb: Haemoglobin, ALT: Alanine Transaminase; AST: Aspartate Amino Transferase; n: No

\section{Discussion}

PNPLA3 rs738409 (C>G) was previously revealed as a major determinant of steatosis in non-alcoholic fatty liver disease $[10,20,21]$, and associated with advanced disease course in alcoholic liver disease [22-24]. But its association with chronic hepatitis $\mathrm{C}$ is not widely studied especially in Middle East and North Africa and remain controversial in other regions.

PNPLA3 rs738409 frequency shows ethnic diversity [17]. Up to our knowledge. The genotype distribution in Egypt and the allele frequency is poorly reported till now. In this study we recorded a minor allele frequency $(G)$ of 0.38 in healthy Egyptians, which when compared to other ethnicities was show to be higher than Afro americans (0.17) and Europeans (0.231) but is lower than Hispanics (0.49). Most importantly this frequency is also higher than that recorded by Ezzikouri et al. [25] from Morocco (0.295) as a middle east country, but this can be explained by the mixed berberic and Arabic ethnicity in their study [25].

Recently, the PNPLA3 rs738409 polymorphism has been reported to be associated with the persistence of HCV [14,25], this association was not addressed before in Egyptians. In the current study we showed an effect of this polymorphism on susceptibility to HCV. This is not matching previous studies from Caucasian and mixed berberic and Arabic studies. This is a quite interesting result that may need further studies to explain it, meanwhile it emphasizes results from previous studies showing that disparities in chronic liver disease burden and prevalence are most likely due to genetic factors in addition to behavioural and environmental factors $[17,26]$. 
A differential gender related effect of the genotype distribution of PNPLA3 rs738409 on susceptibility to $\mathrm{CHC}$ was detected, where significant association of genotypes with susceptibility was shown only in females but not in males. This is like previous reports showing that incidence and evolution of chronic liver disease significantly differs according to gender $[27,28]$.

The association of GG genotype of PNPLA3 rs738409 (C>G) with a higher risk of both advanced liver fibrosis and liver steatosis in CHC has now been confirmed in independent cohorts of Europeans [10,12, 20,21-24,29-31]. Subgroup analysis found that the association with advanced liver fibrosis was stronger among Caucasian populations than Asian populations, although there were no statistically significant differences among them regarding age, BMI, or gender ratio [12]. In Egypt; although having highest prevalence of HCV liver disease burden, this association was not studied adequately yet as far to our knowledge. In this study we show that the presence of the GG genotype is associated with higher fibrosis stages supporting its role as risk genotype and emphasizing the importance of including the test of this polymorphism in the management of HCV patients. This association is independent from other fibrosis risk factors such as age, gender, BMI, platelet count.

Moreover, a gender associated differential effect of PNPLA3 rs738409 genotypes was recorded and showed that PNPLA3 rs738409 homozygous genotype GG is a risk factor for fibrosis in males only but not in females, this is in line with previous studies on the gender related effect of this polymorphism on NAFLD [32], Primary sclerosing cholangitis and alcoholic cirrhosis [33,34]. So up to our knowledge, this is the first confirmation of this genotype gender dependent effect on fibrosis in HCV patients

This study emphasizes the role PNPLA3 rs738409 in persistence and fibrosis severity of CHC course in Egyptians (Upper Africans), and for the first time records its genotype frequencies. Moreover, pinpoints a new role of the PNPLA3 rs738409 CC genotype in susceptibility to CHC. In addition, it shows agreement with previous studies on the association between the PNPLA3 rs738409 GG genotype and severe fibrosis. Most importantly, it shows the gender related impact of PNPLA3 rs738409 on susceptibility and severity of fibrosis. This magnifies the importance of screening high-risk individuals and patients for this polymorphism for better management protocols.

\section{Conclusion}

PNPLA3 rs738409 polymorphism has an impact on HCV persistence and is associated with severe fibrosis in HCV patients, so it can be considered as risk factor for stratification of individuals at high risk of persistent HCV infection especially in females, and for HCV patients at elevated risk of advanced fibrosis specifically in males.

\section{Funding}

This study was funded by Science and technology development grant (STDF) (grant number 4990).

\section{References}

1. Cooke GS, Cooke GS, Lemoine M, Thursz M, Gore C, et al. (2013) Viral hepatitis and the global burden of disease: A need to regroup. J Viral Hepat 20(9): 600-601.

2. Mohd Hanafiah K, Groeger J, Flaxman AD, Wiersma ST (2013) Global epidemiology of hepatitis $\mathrm{C}$ virus infection: new estimates of age-specific antibody to HCV seroprevalence. Hepatology 57(4): 1333-1342.

3. Lauer GM, Walker BD (2001) Hepatitis C virus infection. N Engl J Med 345(1): 41-52.

4. Niederau C, Lange S, Heintges T, Erhardt A, Buschkamp M, et al. (1998) Prognosis of chronic hepatitis C: Results of a large, prospective cohort study. Hepatology 28(6): 1687-1695.

5. Davis GL, Alter MJ, El Serag H, Poynard T, Jennings LW (2010) Aging of hepatitis $\mathrm{C}$ virus (HCV)-infected persons in the United States: a multiple cohort model of HCV prevalence and disease progression. Gastroenterology 138(2): 513-521, 521 e1-e6.

6. Bochud PY, Cai T, Overbeck K, Bochud M, Dufour JF, et al. (2009) Genotype 3 is associated with accelerated fibrosis progression in chronic hepatitis C. J Hepatol 51(4): 655-666.

7. Missiha SB, Ostrowski M, Heathcote EJ (2008) Disease progression in chronic hepatitis C: Modifiable and nonmodifiable factors. Gastroenterology 134(6): 1699-1714.

8. Leandro G, Mangia A, Hui J, Fabris P, Rubbia Brandt L, et al. (2006) Relationship between steatosis, inflammation, and fibrosis in chronic hepatitis C: A meta-analysis of individual patient data. Gastroenterology 130(6): 1636-1642.

9. Wright M, Goldin R, Fabre A, Lloyd J, Thomas H, et al. (2003) Measurement and determinants of the natural history of liver fibrosis in hepatitis C virus infection: a cross sectional and longitudinal study. Gut 52(4): 574-579.

10. Romeo S, Kozlitina J, Xing C, Pertsemlidis A, Cox D, et al. (2008) Genetic variation in PNPLA3 confers susceptibility to nonalcoholic fatty liver disease. Nat Genet 40(12): 1461-1465.

11. Ampuero J, Del Campo JA, Rojas L, García Lozano JR, Solá R, et al. (2014) PNPLA3 rs738409 causes steatosis according to viral \& IL28B genotypes in hepatitis C. Ann Hepatol 13(4): 356-363.

12. Fan JH, Xiang MQ, Li QL, Shi HT, Guo JJ (2016) PNPLA3 rs738409 Polymorphism associated with hepatic steatosis and advanced fibrosis in patients with chronic hepatitis c virus: A meta analysis. Gut Liver 10(3): 456-463.

13. Stattermayer AF, Rutter K, Beinhardt S, Wrba F, Scherzer TM, et al. (2014) Role of FDFT1 polymorphism for fibrosis progression in patients with chronic hepatitis C. Liver Int 34(3): 388-395.

14. Valenti L, Aghemo A, Stättermayer AF, Maggioni P, De Nicola S, et al. (2012) Implications of PNPLA3 polymorphism in chronic hepatitis C patients receiving peginterferon plus ribavirin. Aliment Pharmacol Ther 35(12): 1434-1442.

15. Miyashita M, Ito T, Sakaki M, Kajiwara A, Nozawa H, et al. (2012) Genetic polymorphism in cyclooxygenase-2 promoter affects hepatic inflammation and fibrosis in patients with chronic hepatitis C. J Viral Hepat 19(9): 608-614.

16. Stattermayer AF, Rutter K, Beinhardt S, Scherzer TM, Stadlmayr A, et al. (2012) Association of the IL28B genotype with insulin resistance in patients with chronic hepatitis C. J Hepatol 57(3): 492-498.

17. Pontoriero AC, Trinks J, Hulaniuk ML, Caputo M, Fortuny L, et al. (2015) Influence of ethnicity on the distribution of genetic polymorphisms associated with risk of chronic liver disease in South American populations. BMC Genet 16(1): 93? 
18. Miller SA, Dykes DD, HF Polesky (1988) A simple salting out procedure for extracting DNA from human nucleated cells. Nucleic Acids Res 16(3): 1215.

19. Ohno O, Mizokami M, Wu RR, Saleh MG, Ohba K, et al. (1997) New hepatitis $\mathrm{C}$ virus (HCV) genotyping system that allows for identification of HCV genotypes 1a, 1b, 2a, 2b, 3a, 3b, 4, 5a, and 6a. J Clin Microbiol 35(1): 201-207.

20. Rotman Y, Koh C, Zmuda JM, Kleiner DE, Liang TJ, et al. (2010) The association of genetic variability in patatin-like phospholipase domain-containing protein 3 (PNPLA3) with histological severity of nonalcoholic fatty liver disease. Hepatology 52(2): 894-899.

21. Valenti L, Al Serri A, Daly AK, Galmozzi E, Rametta R, et al. (2010) Homozygosity for the patatin-like phospholipase 3/adiponutrin I148M polymorphism influences liver fibrosis in patients with nonalcoholic fatty liver disease. Hepatology 51(4): 1209-1217.

22. Speliotes EK, Yerges Armstrong LM, Wu J, Hernaez R, et al. (2011) Genome-wide association analysis identifies variants associated with non alcoholic fatty liver disease that have distinct effects on metabolic traits. PLoS Genet 7: e1001324.

23. Donati B, Motta BM, Pingitore P, Meroni M, Pietrelli A, et al. (2016) The rs2294918 E434K variant modulates PNPLA3 expression and liver damage. Hepatology 63(3): 787-798.

24. Tian C, Stokowski RP, Kershenobich D, Ballinger DG, Hinds DA (2010) Variant in PNPLA3 is associated with alcoholic liver disease. Nat Genet 42(1): 21-23.

25. Ezzikouri S, Alaoui R, Tazi S, Nadir S, Elmdaghri N (2014) The adiponutrin I148M variant is a risk factor for HCV-associated liver cancer in North-African patients. Infect Genet Evol 21: 179-183.
26. Nguyen GC, Thuluvath PJ (2008) Racial disparity in liver disease: biological, cultural, or socioeconomic factors. Hepatology 47(3): 1058-1066.

27. Marocchi M, Bernabucci V, Villa E (2015) Gender and the liver. The Italian Journal of Gender Specific Medicine 1(2): 51-57.

28. Buzzetti E, Parikh PM, Gerussi A, Tsochatzis E (2017) Gender differences in liver disease and the drug-dose gender gap. Pharmacol Res 120: 97 108.

29. Valenti L, Rumi M, Galmozzi E, Aghemo A, Del Menico B, et al. (2011) Patatinlike phospholipase domain-containing 3 I148M polymorphism, steatosis, and liver damage in chronic hepatitis C. Hepatology 53(3): 791-799.

30. Cai T, Dufour JF, Muellhaupt B, Gerlach T, Heim M, et al. (2011) Viral genotype-specific role of PNPLA3, PPARG, MTTP, and IL28B in hepatitis C virus-associated steatosis. J Hepatol 55: 529-535.

31. Muller T, Buch S, Berg T, Hampe J, Stickel F (2011) Distinct, alcohol-modulated effects of PNPLA3 genotype on progression of chronic hepatitis $\mathrm{C}$. J Hepatol 55(3): 732-733.

32. Sookoian S, Pirola CJ (2011) Meta-analysis of the influence of I148M variant of patatin-like phospholipase domain containing 3 gene (PNPLA3) on the susceptibility and histological severity of nonalcoholic fatty liver disease. Hepatology 53(6): 1883-1894.

33. Friedrich K, Rupp C, Hov JR, Steinebrunner N, Weiss KH, et al. (2013) A frequent PNPLA3 variant is a sex specific disease modifier in PSC patients with bile duct stenosis. PLoS One 8(3): e58734.

34. Mischitelli M, Mancina R, Ferri F, Farcomeni A, Molinaro A, et al. (2017) Differential gender-related impact of PNPLA3 and CD14 polymorphism on the risk of developing alcoholic cirrhosis. Journal of hepatology. 66(1): S348-S349.
Creative Commons Attribution 4.0 International License

For possible submissions Click Here

\section{Submit Article}

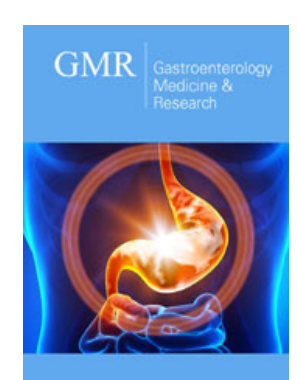

\section{Gastroenterology Medicine \& Research}

\section{Benefits of Publishing with us}

- High-level peer review and editorial services

- Freely accessible online immediately upon publication

- Authors retain the copyright to their work

- Licensing it under a Creative Commons license

- Visibility through different online platforms 